\title{
Surgical Management of Localized Scleroderma
}

Jae Hyun Lee ${ }^{1}$, Soo Yeon Lim ${ }^{1}$, Jang Hyun Lee², Hee Chang Ahn

${ }^{1}$ Department of Plastic and Reconstructive Surgery, Hanyang University College of Medicine, Seoul;

${ }^{2}$ Department of Plastic and Reconstructive Surgery, Hanyang University Guri Hospital, Hanyang University College of Medicine, Guri, Korea

No potential conflict of interest relevant to this article was reported.
Background: Localized scleroderma is characterized by a thickening of the skin from excessive collagen deposits. It is not a fatal disease, but quality of life can be adversely affected due to changes in skin appearance, joint contractures, and, rarely, serious deformities of the face and extremities. We present six cases of localized scleroderma in face from our surgical practice.

Methods: We reviewed six localized scleroderma cases that were initially treated with medication and then received follow-up surgery between April 2003 and February 2015. Six patients had facial lesions. These cases presented with linear dermal sclerosis on the forehead, oval subcutaneous and dermal depression in the cheek.

Results: En coup de sabre $(n=4)$, and oval-shaped lesion of the face $(n=2)$ were successfully treated. Surgical methods included resection with or without Z-plasty $(n=3)$, fat graft $(n=1)$, dermofat graft $(n=1)$, and adipofascial free flap $(n=1)$. Deformities of the affected parts were surgically corrected without reoccurrence.

Conclusion: We retrospectively reviewed six cases of localized scleroderma that were successfully treated with surgery. And we propose an algorithm for selecting the best surgical approach for individual localized scleroderma cases. Although our cases were limited in number and long-term follow-up will be necessary, we suggest that surgical management should be considered as an option for treating scleroderma patients.

Keywords: Localized scleroderma / Linear scleroderma / Morphea / Dermatosclerosis

\section{INTRODUCTION}

Localized scleroderma is characterized by a thickening of the skin from excessive collagen deposits [1]. Localized scleroderma is not a fatal disease, but quality of life is often adversely affected due to changes in skin appearance, joint contractures, and, rarely, serious deformities of the face and extremities [1,2]. It typically occurs in young women [1-3]. Though it is not a hereditary disease, similar conditions can present in close relatives, albeit, rarely $[1-3]$.

In Korea, the prevalence of localized scleroderma is greater among women than men (female-to-male ratio=2.6:1.0) [4] and most patients are between 10 and 20 years old (average age $=26.2$

Correspondence: Hee Chang Ahn

Department of Plastic and Reconstructive Surgery, Hanyang University College of Medicine, 222-1 Wangsimni-ro, Seongdong-gu, Seoul 04763, Korea

E-mail: lawgff9@naver.com

Received August 16, 2017 / Revised September 8, 2017 / Accepted September 8, 2017 years) [4-6].

Medical treatment for localized scleroderma (e.g., immune suppressants) is commonly applied throughout the dermatology field, but clinical improvement from medical management (including significant partial response) is only about 60\% [4]. Due to the limitations of this conservative treatment and patients' expectations for a better quality of life, including aesthetic outcomes, more patients are increasingly preferring surgery over conservative treatment. However, most research into surgical management (e.g., filler [7,8], artificial dermis [9], artificial bone [10], hair transplantation [11,12], and fat or dermofat graft [13-16]) has been case reports, which lack a systemized study design compared with control-design research into medical treatments.

Herein, we discuss our successful experience surgically treating six patients for localized scleroderma. 


\section{METHODS}

We retrospectively reviewed six localized scleroderma cases that were initially treated medically and were subsequently treated with surgery between April 2003 and February 2015. These patients were treated with plastic surgical reconstruction based on their individual needs or their dermatologist's recommendation. Six patients had localized facial lesions. Collectively, the patients had linear dermal sclerosis of the forehead, oval subcutaneous and dermal depression in the cheek. Several surgical methods, including resection with and without Z-plasty for linear-type lesions, fat or dermofat graft, and adipofascial free flap, were applied depending on lesion dimension. All resected tissue was biopsied.

\section{Surgical procedures}

To manage linear scleroderma lesions, we first designed incision lines, and then conducted resection and contracture release. Next, we covered the defect with meticulous suturing in a local flap manner. When necessary to release tension, we performed Zplasty (Table 1; patient no. 1,2,3).

For managing small oval or round scleroderma lesions, we performed fat graft or dermofat graft. A fat graft was made by injecting tumescent solution into the patient's abdomen (2\% lidocaine:bicarb onate:epinephrine, 25:5:1 ratio). Next, we performed liposuction to extract the fats, which were harvested and then centrifuged to make the fat graft. The fat graft was gently injected into the patient's lesions. The dermofat graft was harvested with tissue from the inguinal region, and a slit incision was made where the scar could be hidden among the scleroderma lesion area. After dermofat-graft insertion the site was sutured. When needed, a bolster suture was performed to fix the dermofat graft (Table 1; patient no. 4, 5).

Deep inferior epigastric artery perforator (DIEP) free flaps were used to treat large oval or round scleroderma lesions. After an incision was made where the scar could be hidden, lesions were dissected to make spaces for the DIEP free flaps. Recipient vessels near the scleroderma lesions were dissected as well. Next, the DIEP free flap was elevated and modified with an adipofascial flap and was inserted in the lesion site. Finally, anastomosis was performed with nearby recipient vessels using a microscope and the incision and donor sites were sutured (Table 1; patient no. 6).

\section{RESULTS}

There were a total of six cases (five females and one male) of localized scleroderma, whose mean age was approximately $18.3 \pm 3.0$

Table 1. Patient legends

\begin{tabular}{|c|c|c|c|c|c|c|c|c|c|c|}
\hline $\begin{array}{l}\text { Patient } \\
\text { No. }\end{array}$ & $\begin{array}{l}\text { Sex/Age at } \\
\text { operation }\end{array}$ & $\begin{array}{l}\text { Duration } \\
\text { (yr) }\end{array}$ & Lesion & Biopsy & Dimension ${ }^{\mathrm{a})}$ & $\begin{array}{l}\text { Reconstruction } \\
\text { method }\end{array}$ & Remarks & Medication & $\begin{array}{c}\text { DM } \\
\text { preoperative } \\
\text { F/U period }\end{array}$ & $\begin{array}{c}\text { PS } \\
\text { postoperative } \\
\text { F/U period }\end{array}$ \\
\hline 1 & Female/16 & 9 & Forehead & Sc & $\begin{array}{l}\text { Linear, } \\
6 \times 1 \times 0.7\end{array}$ & $\begin{array}{l}\text { Resection and } \\
\text { primary closure }\end{array}$ & Scar revision & MTX & $9 \mathrm{yr} 8 \mathrm{mo}$ & 6 yr 9 mo \\
\hline 2 & Female/13 & 13 & Forehead & Sc & $\begin{array}{l}\text { Linear, } \\
15 \times 1 \times 0.5\end{array}$ & $\begin{array}{l}\text { Resection and } \\
\text { Z-plasty }\end{array}$ & Scar revision & MTX & 8 yr 6 mo & 6 yr 9 mo \\
\hline 3 & Male/21 & 3 & Forehead & $\mathrm{Sc}$ & $\begin{array}{l}\text { Linear, } \\
8 \times 1 \times 1\end{array}$ & $\begin{array}{l}\text { Resection and } \\
\text { Z-plasty }\end{array}$ & None & MTX & $2 \mathrm{yr} 11 \mathrm{mo}$ & 2 yr 6 mo \\
\hline 4 & Female/18 & 10 & $\begin{array}{l}\text { Cheek, } \\
\text { left }\end{array}$ & Sc & $\begin{array}{c}\text { Oval, } \\
4 \times 2 \times 1.5\end{array}$ & $\begin{array}{l}\text { Dermofat } \\
\text { graft }\end{array}$ & None & MTX & $5 \mathrm{yr}$ & 3 yr 4 mo \\
\hline 5 & Female/21 & 8 & Forehead & Sc & $\begin{array}{l}\text { Oval, } \\
5 \times 2 \times 1\end{array}$ & Fat graft & None & MTX & $1 \mathrm{mo}$ & 2 yr 3 mo \\
\hline 6 & Female/21 & 9 & $\begin{array}{l}\text { Cheek, } \\
\text { right }\end{array}$ & Sc & $\begin{array}{c}\text { Oval, } \\
8 \times 6 \times 2.5\end{array}$ & $\begin{array}{c}\text { Resection and } \\
\text { DIEP adipofascial } \\
\text { free flap }\end{array}$ & None & $\begin{array}{l}\text { Solondo, } \\
\text { Haloxin }\end{array}$ & $1 \mathrm{mo}$ & $14 \mathrm{yr} 1 \mathrm{mo}$ \\
\hline Mean & $18.3 \pm 3.0$ & $8.7 \pm 3.0$ & - & - & - & - & - & - & $4.4 \pm 3.8$ & $6 \pm 4.1$ \\
\hline
\end{tabular}


years (range, 13-21 years). The mean duration (from disease onset to operation) was $8.7 \pm 3.0$ years. Prior to surgery, the mean followup period with dermatology departments was approximately 4.4 \pm 3.8 years, and most of the patients were taking MTX (methotrexate) as a medication. En coup de sabre $(n=4)$, and oval-shaped facial lesions ( $n=2)$ were successfully treated. Our surgical methods included resection with or without Z-plasty $(n=3)$, fat graft $(n=1)$, dermofat graft $(n=1)$, and adipofascial free flap $(n=1)$. All tissue biopsies were confirmed as sclerodermas. After the surgeries, the mean follow-up period with our plastic-surgery department was approximately $6 \pm 4.1$ years (range, $2-14$ years). All deformities were resolved after the operations without any reoccurrences. Only minor complications, such as postoperative scarring, occurred and there were no major complications (Table 1, Figs. 1-3).

\section{Cases}

Thirteen-year-old female with "en coup de sabre" in the mid-fore-
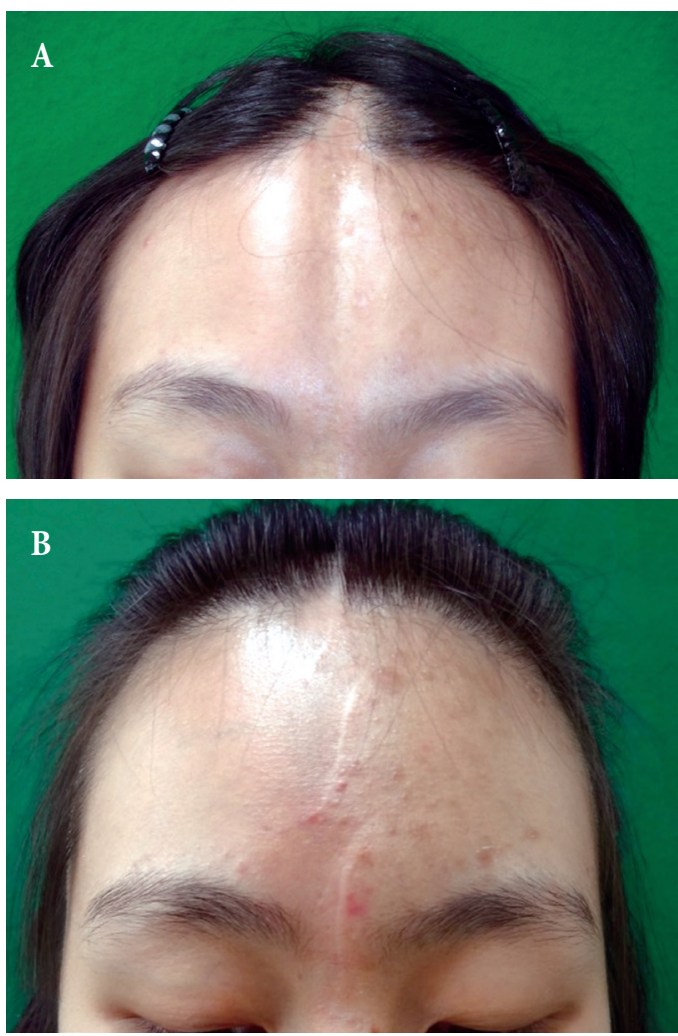

Fig. 1. (A, B) Case of an "en coup de sabre." head: The lesion was resected and the defect was closed with multiple Z-plasties. Preoperative view shows the en coup de sabre in the mid-forehead (Fig. 1A). After one year of follow-up, the contracted contour of the forehead region was resolved (Fig. 1B).

Eighteen-year-old female with a small oval-shaped localized scleroderma $(4 \times 2 \mathrm{~cm})$ in left lower cheek region. The dermofat graft was harvested with tissue from the left inguinal region and a slit incision was made along the lower border of the left mandible body at the scleroderma lesion site. After dissection of the scleroderma lesion area, dermofat graft insertion and suturing was performed. Also, a bolster suture was made to fixate the dermofat graft. Preoperative view shows the localized scleroderma in the left lower cheek region (Fig. 2A). After one year of follow-up, the depressed contour of the left lower cheek region was resolved (Fig. 2B).

Twenty one-year-old female with a large (over $1 / 3$ of hemiface) oval-shaped localized scleroderma $(8 \times 6 \mathrm{~cm})$ in the right lower cheek region. To hide the scar, we extended the lesion incision line from the right tragus area to the right mandible lateral border. Af-
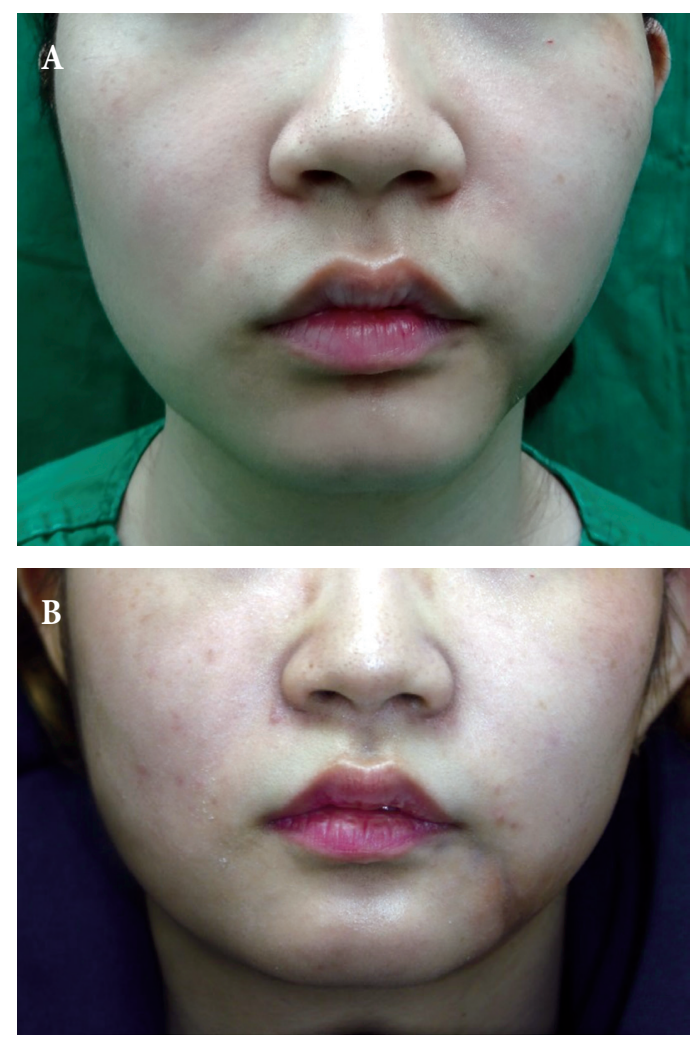

Fig. 2. (A, B) Case of a small scleroderma in face. 

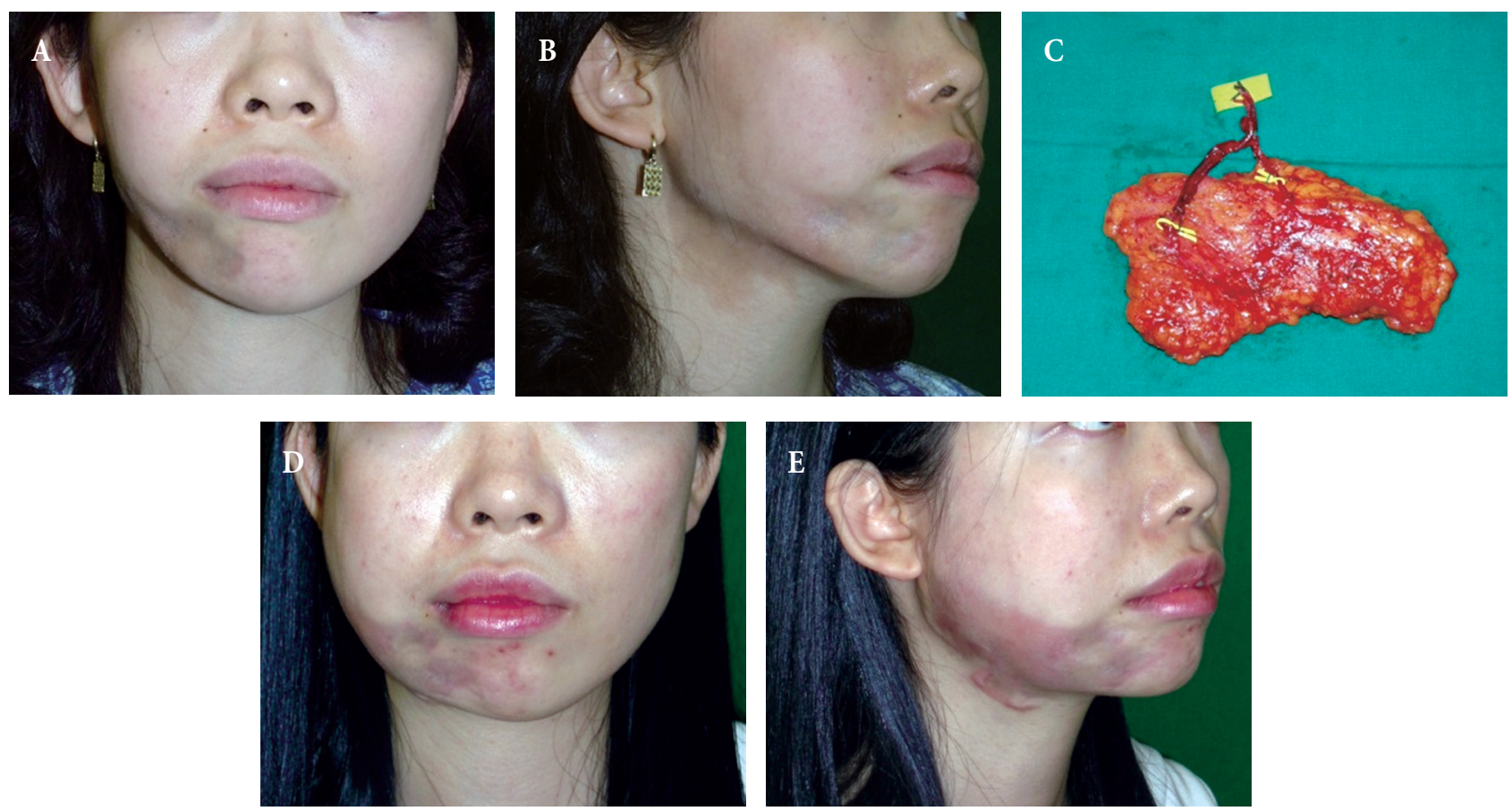

Fig. 3. (A-E) A case of a large scleroderma in face.

ter dissecting the platysma muscle fascia, the harvested DIEP adipofascial free flap $(8 \times 6 \mathrm{~cm}$, Fig. 3C) was inserted into the subfascial layer. Vessel anastomosis was conducted to connect the facial vessels. Fig. 3A, B show preoperative views of the scleroderma and Fig. 3D, E show the patient after one year of follow-up. The depressed contour of the right lower cheek region was resolved with a free-tissue transfer (Fig. 3D, E).

\section{DISCUSSION}

Current dermatological medical treatments for localized scleroderma (e.g., immune suppressants) are usually conservative and often do not yield thoroughly satisfying outcomes for patients. Furthermore, most existing research about surgical management options (e.g., filler [7,8], artificial dermis [9], artificial bone [10], hair transplantation $[11,12]$, or fat or dermofat graft [13-16]) are case reports and, thus, lack a systematic analysis. None of our patients experienced significant clinical improvement with medication and were subsequently referred from the dermatology department. Based on our retrospective review, we propose selecting the appropriate surgical management for different localized scleroderma cases using an algorithm.

When we developed our algorithm (Fig. 4) there were some decisions that we considered prior to performing surgery. As is well established, localized sclerodermas have a 3-5 year self-regression period [2], during which a localized scleroderma patient may consider taking dermatological medications or using this time to observe changes in their symptoms. This was consistent with the mean dermatology preoperative follow-up period (approximately $4.4 \pm 3.8$ years) in the six cases we reviewed in this study. Patients who had an observation period longer than five years tended to prefer surgical treatment. Prior research has shown that treating localized scleroderma during its inactive phase yields a better outcome [3]. Therefore, clinicians should consider each case's individual disease activity when choosing the operation period [2]. Furthermore, when a coexisting bone deformity is suspected, image work-up (e.g., three-dimensional-computed tomography) and bone surgery should be considered [2,17].

Our study offers three distinct benefits: first, we present a new approach for selecting the best surgical mode via an algorithm. 


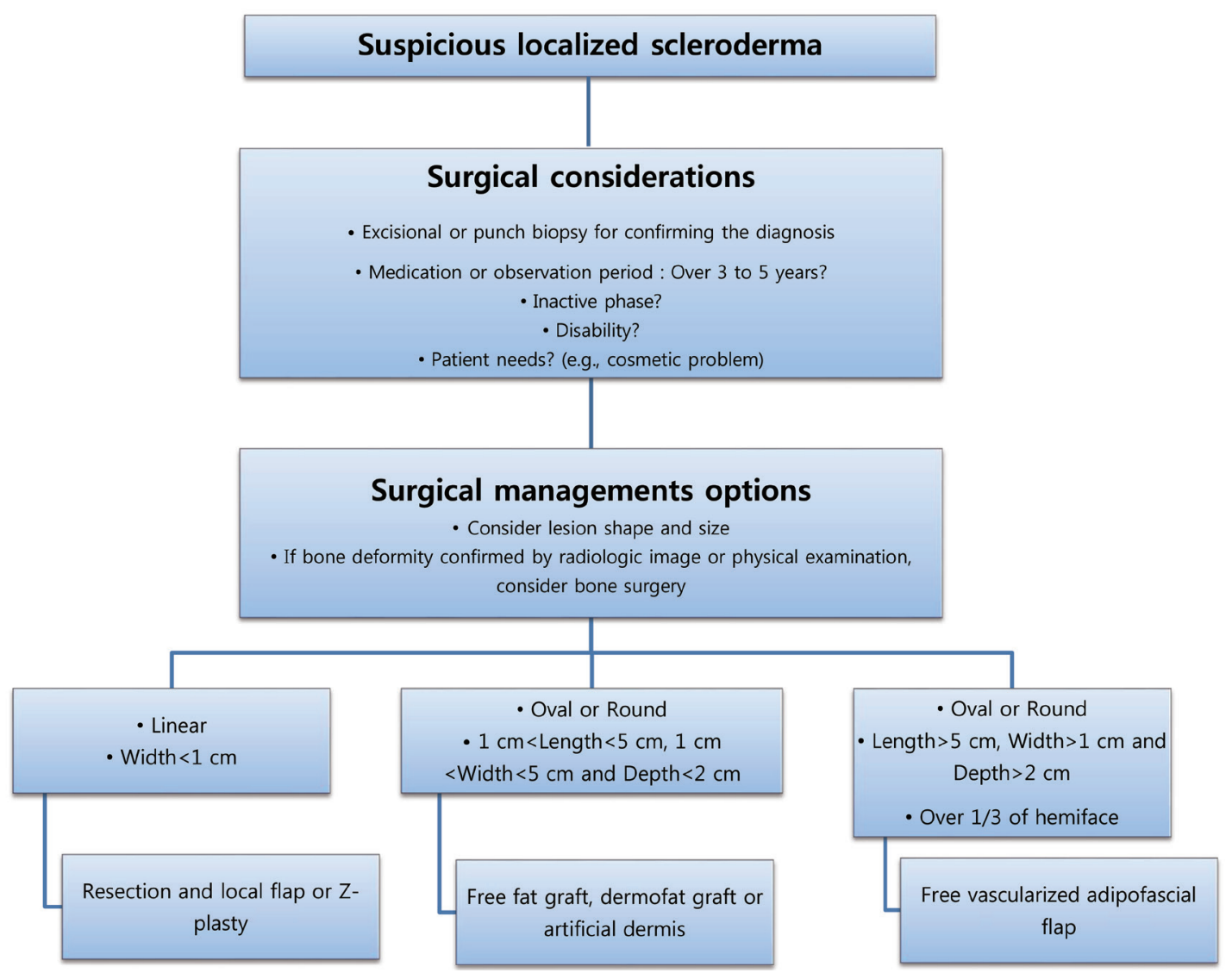

Fig. 4. Algorithm for surgical management of localized scleroderma.

We are the first to suggest a resurfacing algorithm based on lesion dimensions of localized scleroderma. We still recommend considering the potential efficacy of a medical approach as well as the cosmetic expectations of each patient before performing surgery; when taking a surgical approach, we suggest that surgeons consider different methods based on lesion dimensions. Surgical options include resection or contracture release with or without Zplasty for linear type lesions, fat graft or dermofat graft for local lesions, and adipofascial free flap for big regional lesions.

Second, this article highlights the first case of resurfaced localized scleroderma using a free flap. We used an adipofascial free flap to achieve volume replacement on depressed skin contours. Before making the initial flap design, it is important to consider that $70 \%-80 \%$ of the initial flap volume will remain after the surgery at the time of the late postoperative period. Therefore, we elevated $120 \%-140 \%$ of the flap volume for resurfacing a lesion. In this overcorrection manner, we also performed fat graft or dermofat graft at our first attempt.

Third, among the six cases that we reviewed, there were no scleroderma recurrences after five years of follow-up. Also, there were no major complications, only minor complications, such as postoperative scarring.

Because we only reviewed a small number of cases during a short follow-up period, larger studies are needed in the future. Additionally, other new reconstruction methods for treating localized scleroderma, including filler [7,8], artificial dermis [9], artificial bone [10], and hair transplantation $[11,12]$ would be beneficial to this patient population.

\section{PATIENT CONSENT}

The patient provided written informed consent for the publica- 
tion and the use of their images.

\section{REFERENCES}

1. Saxton-Daniels S, Jacobe HT. Chapter 64: morphea. In: Fitzpatrick TB, Wolff K, editors. Fitzpatrick's: dermatology in general medicine. New York: McGraw-Hill Medical; 2012. p.692-701.

2. Careta MF, Romiti R. Localized scleroderma: clinical spectrum and therapeutic update. An Bras Dermatol 2015;90:62-73.

3. Kreuter A, Krieg T, Worm M, Wenzel J, Moinzadeh P, Kuhn A, et al. German guidelines for the diagnosis and therapy of localized scleroderma. J Dtsch Dermatol Ges 2016;14:199-216.

4. Noh JW, Kim J, Kim JW. Localized scleroderma: a clinical study at a single center in Korea. Int J Rheum Dis 2013;16:437-41.

5. Cho HK, Chun SI. A clinical study of localized scleroderma. Korean J Dermatol 1996;34:109-15.

6. Eun C, Lee CW. A clinical study of localized scleroderma in childhood. Korean J Dermatol 1997;35:877-82.

7. Sivek R, Emer J. Use of a blunt-tipped microcannula for soft tissue filler injection in the treatment of linear scleroderma (en coup de sabre). Dermatol Surg 2014;40:1439-41.

8. Franco JP, Serra MS, Lima RB, D’Acri AM, Martins CJ. Scleroderma en coup de sabre treated with polymethylmethacrylate: case report. An Bras Dermatol 2016;91:209-11.
9. Robitschek J, Wang D, Hall D. Treatment of linear scleroderma "en coup de sabre" with AlloDerm tissue matrix. Otolaryngol Head Neck Surg 2008;138:540-1.

10. Hwang DY, Paik HW, Byeon JH. Correction of facial linear scleroderma 'coup de sabre' with BoneSource. J Plast Reconstr Aesthet Surg 2009;62:e25-8.

11. Dai Y, Xu AE, He J. A case report of coup de sabre patient with hair transplantation. J Dermatolog Treat 2017:1-6.

12. Park SW, Wang HY. Survival of grafts in coup de sabre. Dermatol Surg 2002;28:763-6.

13. Ibler KS, Gramkow C, Siemssen PA. Autologous fat transplantation for the treatment of linear scleroderma en coup de sabre. Skinmed 2015;13:74-6

14. Karaaltin MV, Akpinar AC, Baghaki S, Akpinar F. Treatment of "en coup de sabre" deformity with adipose-derived regenerative cell-enriched fat graft. J Craniofac Surg 2012;23:e103-5.

15. Oh CK, Lee J, Jang BS, Kang YS, Bae YC, Kwon KS, et al. Treatment of atrophies secondary to trilinear scleroderma en coup de sabre by autologous tissue cocktail injection. Dermatol Surg 2003;29:1073-5.

16. Barin EZ, Cinal H, Cakmak MA, Tan O. Treatment of linear scleroderma (en coup de sabre) with dermal fat grafting. J Cutan Med Surg 2016;20:269-71.

17. Kim JH, Lee SC, Kim CH, Kim BJ. Facial asymmetry: a case report of localized linear scleroderma patient with muscular strain and spasm. Maxillofac Plast Reconstr Surg 2015;37:29. 